ASTHMA

\title{
Obesity and asthma in 11-12 year old New Zealand children in 1989 and 2000
}

\author{
K Wickens, D Barry, A Friezema, R Rhodius, N Bone, G Purdie, J Crane
}

Thorax 2005;60:7-12. doi: 10.1136/thx.2002.001529

See end of article for authors' affiliations

.....................

Correspondence to: K Wickens, Wellington

Asthma Research Group,

Wellington School of

Medicine and Health

Sciences, P O Box 7343

Wellington South, New

Zealand; kwickens@

wnmeds.ac.nz

Received

11 November 2002

Accepted 27 August 2004
Background: There has been a concurrent increase in the prevalence of obesity and asthma in recent years in New Zealand and other countries.

Methods: Two cross sectional surveys performed in 1989 and 2000 were used to test this association in children of mean age 11.7 years. Body mass index (BMI) was calculated as weight/height ${ }^{2}\left(\mathrm{~kg} / \mathrm{m}^{2}\right)$ and obesity and overweight defined according to an international standard. Standard questions were used to measure the prevalence of asthma symptoms.

Results: Significant increases in the prevalence of reported symptoms and disease between 1989 and 2000 were not explained by a concurrent increase in the prevalence of obesity. In 2000, multivariate analysis showed that increasing BMI standard deviation score was significantly associated with current wheeze $(p=0.002)$, inhaled steroid use $(p=0.004)$, and the use of any medication $(p=0.001)$. None of the associations was significantly different for boys or girls.

Conclusion: There is some evidence for an association of obesity with asthma symptoms and treatment but this does not explain the increasing prevalence of this disease.
$\mathrm{T}$ here is convincing evidence that body mass index (BMI) has increased in the last 10-30 years in developed countries, ${ }^{1}$ including New Zealand. ${ }^{23}$ A rise in the prevalence of asthma in these countries seems to have occurred over the same time period. ${ }^{45}$ BMI has been associated with asthma symptoms and severity in a large number of studies of adults ${ }^{6-9}$ and children, ${ }^{10-14}$ although in some populations the association is limited to girls ${ }^{11}{ }^{13}{ }^{14}$ and women. ${ }^{67}$ Although sex interaction terms were seldom reported in these studies, the possibility of a sex specific effect needs further investigation. Evidence that the obesity/ asthma association may be causal is provided by two small randomised controlled trials of obese asthmatic adults where weight reduction was accompanied by an improvement in lung function, symptom scores, and peak flow variability. ${ }^{16}{ }^{17}$ Thus, while BMI and asthma symptom reporting have both increased over time and occur together more often than would be expected by chance, few studies ${ }^{18}$ have been able to show how much of the increase in asthma symptoms over time is due to increases in BMI during the same time period. The present study investigates changing asthma prevalence and its association with obesity among 11-12 year old boys and girls between 1989 and 2000 in a New Zealand population.

\section{METHODS}

Cross sectional prevalence studies of children attending schools in the City of Hastings and in the borough of Havelock North were conducted in 1989 and 2000. All children in the 1989 survey turned 12 in the survey year (mean age 11.7 years). In 2000 the study population comprised a broader age range of children (mean age 11.4 years) but, for analysis comparing study years this data set was restricted to children in their 12th year (mean age 11.7). The principals of schools qualifying for the study distributed a parental/caregiver questionnaire and consent form. The questionnaires collected information on the child's ethnicity (Maori, European, Pacific Island group, other) and gender. In 2000, standard International Study of Asthma and Allergies in Childhood (ISAAC) questions were used to collect information on the prevalence of asthma symptoms. ${ }^{19}$ At times these differed slightly from the questions used in 1989. In 1989, having a history of wheeze was defined as a positive response to the question "Has a wheeze-that is, a whistling noise (high or low pitched)—ever been heard coming from the child's chest?" The equivalent question in 2000 was "Has your child ever had wheezing or whistling in the chest at any time in the past?" In 1989 current wheeze was defined as a response of once or more to "How many times has it occurred in the last 12 months?" In 2000 current wheeze was defined as a positive response to the question "Has your child had wheezing or whistling in the chest in the last 12 months?" In 1989 respondents were asked "Has your child ever suffered from any of the following?" with a positive response to "asthma" defining this condition. The equivalent question in 2000 was "Has your child ever had asthma?" The same questions were used in 1989 and 2000 to define wheezing on exercise, hospital admissions, and medication use.

Following parental consent, eligible children underwent an exercise challenge indoors at school, as previously outlined, ${ }^{4}$ to test for airway hyperresponsiveness. Identical methods and the same equipment were used for measuring weight and height of children in each year. Height was measured to the nearest $0.1 \mathrm{~cm}$ using a portable field instrument that has been shown to be accurate by comparison with a standard rule. The child stands on a flat base, heels and back against an upright pylon. The movable part of the pylon surrounds the fixed part on three sides, has a fixed head piece and a pointer at its lowest border. Children were weighed in light clothing on calibrated step scales and weight was recorded to the nearest kilogram. Each child ran briskly for 6 minutes, radial pulse rate was recorded at rest and immediately after the run. Five peak flow rate (PEFR) measurements were made before and 5 minutes after exercise using the same standard (clockface) Wright PEFR meters in both studies. The change in peak flow after exercise was calculated as the mean of the highest three post-exercise peak flow measurements as a percentage of the mean of the highest three pre-exercise peak flow measurements. Exercise induced 
bronchospasm was defined as a fall in peak flow of more than $15 \%$. If children had received short acting $\beta_{2}$ agonists within 6 hours of the exercise challenge they were exercised, and if their PEFR decreased by less than 15\% from the baseline they were re-exercised on another occasion without prior $\beta_{2}$ agonist exposure.

To ensure comparability between survey years, the study commenced in February in each year, the exercise challenge procedure was undertaken by the same nurse (NB) in both years, and the PEFR measurements were supervised by the same investigator (DB). Temperature and humidity were measured using a whirling hygrometer just before each set of exercise challenges.

The only difference between years was that skin prick testing to common environmental allergens was performed before the exercise challenge in 2000. This was undertaken as part of the ISAAC phase II protocol using ALK allergens (ALK Allergologisk Laboratorium A/s, Horsholm, Denmark) (Dermatophagoides pteronyssinus, Dermatophagoides farinae, Felis domesticus, Alternaria, mixed grasses, mixed trees) and positive and negative controls. A positive reaction was defined as a mean wheal diameter of $3 \mathrm{~mm}$ or greater to an allergen with atopy defined as any positive reaction.

Ethical approval was obtained from the Hawkes Bay ethics committee.

\section{Statistical analysis}

Data analysis was conducted using SAS version 8 (SAS Institute Inc, Cary, NC, USA). Only observations with complete height and weight data were included in the analysis. Missing data were treated identically in both survey years. A small number $(<6)$ of non-responders to the health outcome questions were classified with those responding negatively, as previously in ISAAC. For all other variables, respondents with missing values were excluded from the analysis. Inhaled steroid and cromoglycate use in the last 12 months were combined as one variable. BMI was calculated as weight/height ${ }^{2}\left(\mathrm{~kg} / \mathrm{m}^{2}\right)$. The definition of obesity and overweight in this population of children was based on a standard international definition which used pooled international BMI data and is linked to the widely used adult overweight $\left(25 \mathrm{~kg} / \mathrm{m}^{2}\right)$ and obesity $\left(30 \mathrm{~kg} / \mathrm{m}^{2}\right)$ definitions. ${ }^{20}$ There is no similar agreed international definition of underweight. Using New Zealand BMI curves, ${ }^{21}$ we extrapolated from a BMI of 18.5 at age 18 to determine a BMI cut off of 15.2 in boys and 15.1 in girls, below which children in this study were considered underweight.

The standard deviation score (SDS) for BMI was calculated adjusting for age for boys and girls separately using the combined years. Logistic regression analysis was used to determine the effects of study year on the prevalence of the dependent variables (prevalence and history of wheeze, asthma, hospital admissions, bronchial hyperresponsiveness (BHR) and asthma medication use) before and after adjustment for BMI (obese, overweight, underweight versus normal weight), ethnicity and sex. Within year associations of obesity, overweight and underweight with the outcome variables were also examined using logistic regression analysis. For year 2000 the full dataset $(n=1287)$ was used to adjust for the potential confounding effects of family history of allergic disease, family size, birth weight, current smoking in the home, father's years of education, frequency of exercise and hamburger consumption, as well as ethnicity, sex and year of birth. After the exclusion of respondents with missing data for family size, birth weight, ethnicity, hamburger consumption, and exercise frequency there were 1237 respondents included in these models. $p$ values are reported for the null hypothesis of no trend with BMI SDS. Differences in the association of BMI SDS with the outcome variables between years and between the sexes were tested using interaction terms. The criteria for concluding significance were adjusted to take into account multiple outcome variables using the Holm's method. ${ }^{22}$ Unadjusted p values are reported. Odds ratios and confidence intervals for comparisons between the normal BMI and other categories are given.

\section{RESULTS}

In 1989, 12 of the 13 school principals in the study area agreed to their school participating in the research and, in 2000, all school principals agreed to participate. The prevalence questionnaire response rate was $94 \%(n=873)$

\begin{tabular}{|c|c|c|c|}
\hline & $\begin{array}{l}1989 \\
(N=871)\end{array}$ & $\begin{array}{l}2000^{*} \\
(N=894)\end{array}$ & $\begin{array}{l}2000 t \\
(N=1287)\end{array}$ \\
\hline \multicolumn{4}{|l|}{ Body mass index } \\
\hline Obese & $2.6(23)$ & $8.7(78)$ & $8.1(104)$ \\
\hline Overweight & $11.9(104)$ & $22.5(201)$ & $21.0(270)$ \\
\hline Normal weight & $76.3(665)$ & $66.6(595)$ & $68.1(877)$ \\
\hline Underweight & $9.1(79)$ & $2.2(20)$ & $2.8(36)$ \\
\hline Male sex & $52.1(454)$ & $49.7(444)$ & $50.2(645)$ \\
\hline Mean (range) age (years) & $11.7(11.1-12.2)$ & $11.7(11.1-12.3)$ & $11.5(10.1-12.6)$ \\
\hline \multicolumn{4}{|l|}{ Ethnicity } \\
\hline Maori & $25.8(225)$ & $30.8(275)$ & $30.6(394)$ \\
\hline European & $66.8(582)$ & $62.8(561)$ & $62.3(802)$ \\
\hline Pacific Island & $3.1(27)$ & $4.5(40)$ & $4.8(62)$ \\
\hline Other & $1.0(9)$ & $1.5(13)$ & $1.6(20)$ \\
\hline Missing & $3.2(28)$ & $0.5(5)$ & $0.7(9)$ \\
\hline Wheeze ever & $26.2(228)$ & $44.7(400)$ & $44.1(567)$ \\
\hline Wheeze in last 12 months & $17.7(154)$ & $23.3(208)$ & $22.0(283)$ \\
\hline Wheeze with exercise & $14.8(129)$ & $23.8(213)$ & $22.8(293)$ \\
\hline Asthma ever & $16.9(147)$ & $37.0(331)$ & $35.7(460)$ \\
\hline Hospital admission ever & $8.5(74)$ & $13.4(120)$ & $14.0(180)$ \\
\hline \multicolumn{4}{|c|}{ Inhaled steroid or cromoglycate in last } \\
\hline 12 months & $5.5(48)$ & $16.1(144)$ & $15.5(200)$ \\
\hline Any medication in last 12 months & $12.7(111)$ & $25.2(225)$ & $24.3(313)$ \\
\hline BHR to exercise & $12.3(107 / 868)$ & $9.0(80 / 892)$ & $8.4(108 / 1284)$ \\
\hline Atopy & - & $37.5(334 / 891)$ & $34.7(444 / 1281)$ \\
\hline $\begin{array}{l}\text { BHR, bronchial hyperresponsiveness. } \\
\text { *2000 data restricted to children in th } \\
\text { †Unrestricted } 2000 \text { dataset. }\end{array}$ & eir 12 th year. & & \\
\hline
\end{tabular}


Table 2 Unadjusted and adjusted OR $(95 \% \mathrm{Cl})$ showing associations for study year and underweight, overweight, and obesity versus normal weight in the combined dataset

\begin{tabular}{|c|c|c|c|c|c|c|c|}
\hline & \multirow{3}{*}{$\begin{array}{l}\text { Unadjusted } \\
\text { Year } \\
2000+\text { v } 1989\end{array}$} & \multicolumn{5}{|l|}{ Adjusted¥ } & \multirow{3}{*}{$\begin{array}{l}\text { P value for trenc } \\
\text { with BMI SDS }\end{array}$} \\
\hline & & \multirow{2}{*}{$\begin{array}{l}\text { Year } \\
2000+v 1989\end{array}$} & \multicolumn{4}{|l|}{ Body mass index } & \\
\hline & & & Underweight & Normal & Overweight & Obese & \\
\hline Wheeze ever & $2.28(1.87 \text { to } 2.79)^{* *}$ & $2.29(1.85 \text { to } 2.83)^{* *}$ & 1.01 (0.63 to 1.62$)$ & 1.00 & 1.25 (0.96 to 1.64$)$ & 1.26 (0.82 to 1.93$)$ & 0.03 \\
\hline Wheeze last 12 months & $1.41(1.12 \text { to } 1.78)^{\star *}$ & 1.33 (1.04 to 1.70$)$ & $0.77(0.42$ to 1.38$)$ & 1.00 & $1.36(1.00$ to 1.84$)$ & 1.69 (1.06 to 2.69$)$ & $0.002^{*}$ \\
\hline Wheeze with exercise & $1.80(1.41 \text { to } 2.29)^{* *}$ & $1.72(1.34 \text { to } 2.22)^{* *}$ & $0.81(0.44$ to 1.50$)$ & 1.00 & $1.22(0.89$ to 1.67$)$ & $1.76(1.11$ to 2.80$)$ & $0.003^{*}$ \\
\hline Asthma ever & $2.90(2.32 \text { to } 3.62)^{* *}$ & $2.88(2.28 \text { to } 3.64)^{\star *}$ & $1.17(0.69$ to 1.96$)$ & 1.00 & 1.08 (0.81 to 1.44$)$ & 1.39 (0.90 to 2.17$)$ & 0.08 \\
\hline Hospital admission ever & $1.66(1.22 \text { to } 2.25)^{\star *}$ & 1.61 (1.17 to 2.23$)$ & $1.08(0.50$ to 2.31$)$ & 1.00 & 1.08 (0.72 to 1.60$)$ & 1.18 (0.66 to 2.12 ) & 0.98 \\
\hline $\begin{array}{l}\text { Inhaled steroid or cromoglycate } \\
\text { in last } 12 \text { months }\end{array}$ & $3.29(2.34 \text { to } 4.63)^{* *}$ & $3.20(2.24 \text { to } 4.68)^{* *}$ & 1.33 (0.64 to 2.78$)$ & 1.00 & 1.23 (0.83 to 1.83$)$ & 2.33 (1.38 to 3.94$)$ & $0.002^{*}$ \\
\hline $\begin{array}{l}\text { Any medication in last } \\
12 \text { months }\end{array}$ & $2.30(1.79 \text { to } 2.96)^{* *}$ & $2.20(1.70 \text { to } 2.85)^{* *}$ & $0.95(0.52$ to 1.72$)$ & 1.00 & 1.08 (0.79 to 1.50$)$ & 1.82 (1.15 to 2.89 ) & $0.005^{*}$ \\
\hline BHR to exercise & $0.70(0.52 \text { to } 0.95)^{*}$ & 0.71 (0.51 to 0.97$)$ & 1.28 (0.69 to 2.39 ) & 1.00 & $1.21(0.81$ to 1.83$)$ & $0.93(0.45$ to 1.93$)$ & 0.90 \\
\hline
\end{tabular}

in 1989 and $84 \%$ in the full $(n=1321) 2000$ dataset. Among the children who returned questionnaires, height and weight were measured for $99.8 \%(n=871)$ in $1989,97.4 \%$ in the full 2000 dataset $(n=1287)$, and $97.3 \%$ in the 2000 dataset restricted to children in their 12 th year $(n=894)$. Of these, $99.7 \%(\mathrm{n}=868)$ in $1989,99.8 \%$ in the full $(\mathrm{n}=1284)$ and restricted $(\mathrm{n}=892) 2000$ datasets completed the exercise challenge. Skin prick tests were completed on $99.5 \%$ $(n=1281)$ of the full and $99.7 \%(n=891)$ of the restricted 2000 datasets.

Table 1 shows that, between 1989 and 2000, the prevalence of overweight children had doubled, the prevalence of obese children had tripled, and the prevalence of underweight children was a quarter of the 1989 prevalence. Corresponding to this, between 1989 and 2000 there was a doubling in the prevalence of a history of wheeze, asthma and any asthma medication use in the past 12 months, three times the use of inhaled steroid or cromoglycate in the last 12 months, and smaller but substantial increases in current wheeze and hospital admissions. In contrast, there was a decline in the prevalence of a positive exercise challenge, with boys accounting for most of this decline (data not shown).

The odds of having a history of diagnosed asthma or symptoms or using medication in 2000 compared with 1989 were significantly increased and were not explained by changes in the prevalence of obesity, ethnicity and sex over this time period (table 2). In this dataset, where both years are combined, there were significant trends in BMI SDS for the prevalence of symptoms and medication use.

In 1989 there was little evidence that BMI SDS was associated with any outcome (table 3). By 2000 there were significant trends in BMI SDS for all symptom and disease outcomes, inhaled steroid (including cromoglycate) use, and any medication use. Subgroup analyses according to sex showed that these trends remained significant for girls only. However, after adjustment for multiple comparisons, none of the associations with BMI SDS was significantly different for boys or girls in either year. There were also no significant between year differences in associations of BMI SDS with any outcome.

Table 4 shows the year 2000 associations of BMI groups with each outcome adjusted for potential confounders (mostly available for year 2000 only). The strength of the BMI group associations and significance of BMI SDS trend with current wheeze, inhaled steroid (including cromoglycate) use, and any medication use were similar to the univariate associations. However, after adjustment for confounders, the significance of increasing BMI SDS for having a history of wheeze or asthma and wheeze with exercise reduced. The associations were not significantly different for boys or girls. Nevertheless, there were significant trends in increasing BMI SDS with increases in asthma disease and symptom reporting and the use of inhaled steroids and other medication in girls only.

\section{DISCUSSION}

The results show clearly that there have been large increases in the prevalence of reported asthma symptoms between 1989 and 2000 in New Zealand, reflected also in increased medication use for asthma. There was a parallel increase in BMI during the same time period. However, since there was little change in the associations between survey year and outcomes after adjusting for BMI, we conclude that increases in BMI are unlikely to explain the increase in asthma symptoms. A similar conclusion was reached in another study investigating whether an increase in BMI contributed to the rise in asthma in British children between 1982 and 1994..$^{18}$

Although the associations of BMI with asthma symptoms in 2000 were stronger than in 1989, these differences were not significant. Thus, this study does not provide evidence of a change in these associations over time. In contrast, a recent review by Chinn et $a^{23}$ concludes that, in children at least, the association between obesity and asthma is recent. In support of this they cite earlier studies where obesity has not been shown to be associated with asthma. For example, in a large cohort of British children born in 1958 Peckham et al ${ }^{24}$ showed that, at age 11 , children with frequent current asthma attacks and/or wheezy bronchitis had lower mean relative weight. A later analysis of this cohort, ${ }^{25}$ which distinguished between asthmatic and wheezy bronchitic children, showed that although there was no significant association of BMI with asthma at age 7, wheezy bronchitic children had a higher BMI than non-wheezy bronchitic children at age 7 and than asthmatics at age 11. In 1977 a second study ${ }^{26}$ in England and Scotland in children aged 5-11 showed a higher prevalence of the symptom "chest ever wheezy" among overweight children. The authors of the 1958 cohort study ${ }^{25}$ report that definitions of asthma changed as the cohort aged. The definition of asthma has continued to evolve and, although it is no longer fashionable to collect data on "wheezy bronchitis", "wheeze" is a central characteristic of current definitions. Thus, part of the problem in understanding the association between obesity and asthma is due to poor and changing definitions of the disease, making it 
Table 3 Univariate OR $(95 \% \mathrm{Cl})$ showing associations for underweight, overweight, and obesity versus normal weight in 1989 and 2000 among all children, girls and boys $\uparrow$

\begin{tabular}{|c|c|c|c|c|c|c|}
\hline \multirow[b]{3}{*}{ Outcome variables } & \multicolumn{2}{|l|}{ All } & \multicolumn{2}{|l|}{ Girls } & \multicolumn{2}{|l|}{ Boys } \\
\hline & \multirow{2}{*}{$\begin{array}{l}1989 \\
\text { Total }(n=871)\end{array}$} & \multirow{2}{*}{$\begin{array}{l}2000+ \\
\text { Total }(n=894)\end{array}$} & \multirow{2}{*}{$\begin{array}{l}1989 \\
\text { Total }(n=417)\end{array}$} & \multirow{2}{*}{$\begin{array}{l}2000 t \\
\text { Total }(n=449)\end{array}$} & \multirow{2}{*}{$\begin{array}{l}1989 \\
\text { Total }(n=454)\end{array}$} & \multirow{2}{*}{$\begin{array}{l}2000 \dagger \\
\text { Total }(n=444)\end{array}$} \\
\hline & & & & & & \\
\hline \multicolumn{7}{|l|}{ Wheeze ever } \\
\hline Underweight & $1.00(0.58$ to 1.70$)$ & $0.71(0.28$ to 1.81$)$ & 1.01 (0.45 to 2.31$)$ & $0.33(0.07$ to 1.53$)$ & $1.04(0.51$ to 2.13$)$ & $1.80(0.42$ to 7.67$)$ \\
\hline Normal & 1.00 & 1.00 & 1.00 & 1.00 & 1.00 & 1.00 \\
\hline Overweight & $1.30(0.83$ to 2.05$)$ & $1.26(0.91$ to 1.74$)$ & $1.36(0.69$ to 2.70$)$ & $1.50(0.96$ to 2.35$)$ & $1.34(0.73$ to 2.46$)$ & $1.08(0.68$ to 1.72$)$ \\
\hline Obese & $1.28(0.52$ to 3.17$)$ & $1.32(0.82$ to 2.12 ) & $1.40(0.37$ to 5.31$)$ & 1.81 (0.95 to 3.42$)$ & 1.28 (0.37 to 4.48 ) & 0.96 (0.47 to 1.95$)$ \\
\hline$p$ valuef & 0.30 & $0.006^{*}$ & 0.67 & $0.0005^{* *}$ & 0.34 & 0.87 \\
\hline \multicolumn{7}{|c|}{ Wheeze last 12 months } \\
\hline Underweight & $0.96(0.51$ to 1.80$)$ & $0.19(0.03$ to 1.45$)$ & 1.16 (0.46 to 2.94$)$ & 0.34 (0.04 to 2.71$)$ & $0.87(0.37$ to 2.05$)$ & $\S$ \\
\hline Normal & 1.00 & 1.00 & 1.00 & 1.00 & 1.00 & 1.00 \\
\hline Overweight & 1.47 (0.89 to 2.42$)$ & 1.31 (0.90 to 1.89$)$ & 1.77 (0.85 to 3.73$)$ & $1.21(0.72$ to 2.05$)$ & $1.32(0.67$ to 2.60$)$ & $1.42(0.84$ to 2.40$)$ \\
\hline Obese & $1.03(0.34$ to 3.08$)$ & 1.82 (1.09 to 3.03 ) & $1.36(0.29$ to 6.41$)$ & $1.58(0.78$ to 3.21$)$ & $0.86(0.18$ to 4.05$)$ & 2.19 (1.04 to 4.59$)$ \\
\hline$p$ valuef & 0.22 & $0.002^{*}$ & 0.44 & $0.013^{*}$ & 0.36 & 0.08 \\
\hline \multicolumn{7}{|l|}{ Wheeze with exercise } \\
\hline Underweight & 1.05 (0.55 to 2.01$)$ & $0.19(0.02$ to 1.39$)$ & $0.69(0.24$ to 2.04$)$ & $\S$ & 1.45 (0.63 to 3.23$)$ & $0.49(0.06$ to 4.02$)$ \\
\hline Normal & 1.00 & 1.00 & 1.00 & 1.00 & 1.00 & 1.00 \\
\hline Overweight & 0.99 (0.55 to 1.78$)$ & $1.29(0.89$ to 1.86$)$ & $1.49(0.70$ to 3.19$)$ & $1.28(0.77$ to 2.14$)$ & $0.59(0.23$ to 1.55$)$ & $1.30(0.77$ to 2.20$)$ \\
\hline Obese & $1.63(0.59$ to 4.48$)$ & 1.75 (1.05 to 2.92$)$ & $1.28(0.27$ to 6.05$)$ & $1.69(0.84$ to 3.38$)$ & $2.04(0.52$ to 7.93$)$ & $1.86(0.87$ to 3.94$)$ \\
\hline $\mathrm{p}$ valuef & 0.89 & $0.0006^{* *}$ & 0.47 & $0.004^{*}$ & 0.61 & 0.05 \\
\hline \multicolumn{7}{|l|}{ Asthma ever } \\
\hline Underweight & $1.03(0.56$ to 1.90$)$ & 1.01 (0.40 to 2.57$)$ & $0.82(0.31$ to 2.20$)$ & $0.49(0.11$ to 2.28$)$ & 1.26 (0.57 to 2.78 ) & 2.47 (0.58 to 10.54$)$ \\
\hline Normal & 1.00 & 1.00 & 1.00 & 1.00 & 1.00 & 1.00 \\
\hline Overweight & $0.74(0.41$ to 1.35$)$ & $1.27(0.91$ to 1.76$)$ & $0.90(0.38$ to 2.12$)$ & 1.52 (0.95 to 2.42$)$ & $0.65(0.28$ to 1.49$)$ & $1.10(0.69$ to 1.76$)$ \\
\hline Obese & 1.01 (0.34 to 3.02 ) & 1.61 (1.00 to 2.58$)$ & $1.18(0.25$ to 5.57$)$ & 2.45 (1.29 to 4.66$)$ & 0.90 (0.19 to 4.27$)$ & $1.04(0.51$ to 2.13$)$ \\
\hline $\mathrm{p}$ valuef & 0.73 & $0.004^{*}$ & 0.82 & $0.0001^{* *}$ & 0.50 & 1.00 \\
\hline \multicolumn{7}{|c|}{ Hospital admission ever } \\
\hline Underweight & $0.40(0.12$ to 1.33$)$ & 2.50 (0.88 to 7.09$)$ & 0.31 (0.04 to 2.37$)$ & 4.11 (1.17 to 14.46$)$ & $0.49(0.11$ to 2.11$)$ & $0.99(0.12$ to 8.23$)$ \\
\hline Normal & 1.00 & 1.00 & 1.00 & 1.00 & 1.00 & 1.00 \\
\hline Overweight & $0.73(0.32$ to 1.63$)$ & $1.42(0.90$ to 2.23$)$ & $1.02(0.34$ to 3.06$)$ & $1.04(0.51$ to 2.11$)$ & $0.53(0.16$ to 1.79$)$ & 1.86 (1.03 to 3.39$)$ \\
\hline Obese & $2.11(0.69$ to 6.40$)$ & $1.50(0.79$ to 2.86$)$ & $1.13(0.14$ to 9.15$)$ & $1.83(0.78$ to 4.29$)$ & $3.20(0.81$ to 12.57$)$ & $1.19(0.44$ to 3.25$)$ \\
\hline$p$ valuef & 0.32 & 0.27 & 0.42 & 0.43 & 0.54 & 0.43 \\
\hline \multicolumn{7}{|c|}{ Inhaled steroid or cromoglycate in last 12 months } \\
\hline Underweight & $1.86(0.79$ to 4.36$)$ & $0.66(0.15$ to 2.89$)$ & 2.38 (0.63 to 9.02$)$ & 0.54 (0.07 to 4.32$)$ & $1.69(0.55$ to 5.18$)$ & $0.83(0.10$ to 6.95$)$ \\
\hline Normal & 1.00 & 1.00 & 1.00 & 1.00 & 1.00 & 1.00 \\
\hline Overweight & $1.38(0.59$ to 3.21$)$ & $1.21(0.78$ to 1.86$)$ & $1.18(0.25$ to 5.54$)$ & $0.97(0.51$ to 1.84$)$ & $1.56(0.57$ to 4.32$)$ & $1.48(0.82$ to 2.68$)$ \\
\hline Obese & $0.87(0.11$ to 6.66$)$ & 2.33 (1.35 to 4.00$)$ & $2.73(0.32$ to 23.30$)$ & $3.09(1.53$ to 6.26$)$ & $\dagger+$ & $1.52(0.62$ to 3.69$)$ \\
\hline$p$ valuef & 0.80 & $0.002^{*}$ & 0.89 & $0.0008^{* *}$ & 0.85 & 0.42 \\
\hline \multicolumn{7}{|c|}{ Medication in last 12 months } \\
\hline Underweight & $1.08(0.55$ to 2.11$)$ & $0.58(0.17$ to 2.02$)$ & 0.67 (0.19 to 2.27$)$ & $0.67(0.14$ to 3.12$)$ & $1.48(0.65$ to 3.40$)$ & $0.47(0.06$ to 3.87$)$ \\
\hline Normal & 1.00 & 1.00 & 1.00 & 1.00 & 1.00 & 1.00 \\
\hline Overweight & $0.77(0.36$ to 1.41$)$ & 1.25 (0.87 to 1.80$)$ & 0.69 (0.23 to 2.03$)$ & $1.18(0.71$ to 1.97$)$ & $0.74(0.30$ to 1.82$)$ & 1.32 (0.79 to 2.22$)$ \\
\hline Obese & $1.00(0.29$ to 3.42$)$ & 1.96 (1.19 to 3.22$)$ & $1.69(0.35$ to 8.02$)$ & 2.31 (1.19 to 4.45$)$ & 0.56 (0.07 to 4.43$)$ & $1.57(0.73$ to 3.37$)$ \\
\hline $\mathrm{p}$ valuef & 0.62 & $0.0007^{* *}$ & 0.85 & $0.001^{* *}$ & 0.40 & 0.18 \\
\hline \multicolumn{7}{|l|}{ BHR to exercise } \\
\hline Underweight & $1.47(0.76$ to 2.85$)$ & $0.53(0.07$ to 4.02$)$ & 1.64 (0.64 to 4.23$)$ & 0.75 (0.09 to 5.99$)$ & 1.35 (0.53 to 3.42$)$ & $\S$ \\
\hline Normal & 1.00 & 1.00 & 1.00 & 1.00 & 1.00 & 1.00 \\
\hline Overweight & 1.67 (0.95 to 2.93 ) & 1.05 (0.60 to 1.81$)$ & $2.10(0.96$ to 4.59$)$ & $0.94(0.46$ to 1.95$)$ & 1.34 (0.59 to 3.04$)$ & 1.15 (0.50 to 2.67$)$ \\
\hline Obese & $1.20(0.35$ to 4.12$)$ & $0.87(0.36$ to 2.10$)$ & $0.82(0.10$ to 6.58$)$ & $0.87(0.29$ to 2.59$)$ & $1.60(0.34$ to 7.66$)$ & $0.77(0.17$ to 3.44$)$ \\
\hline$p$ valuef & 0.85 & 0.87 & 0.92 & 0.78 & 0.88 & 0.90 \\
\hline
\end{tabular}

BHR, bronchial hyperresponsiveness.

*Meets the Holm's criterion for significance (adjusting for eight comparisons) at the $5 \%$ level. ${ }^{22}$

${ }^{* *}$ Meets the Holm's criterion for significance (adjusting for eight comparisons) at the $1 \%$ level. ${ }^{22}$

†2000 data restricted to children in their 12 th year.

fp value for trend with BMI SDS.

TOne observation is missing information on sex in year 2000.

$\S$ No underweight subjects with this outcome.

††No obese subjects with this outcome.

difficult to conclude that associations with obesity in children are recent.

Reporting bias may explain associations of asthma with obesity if dyspnoea in obese children is interpreted as a symptom of asthma by clinicians. In support of this, we found that BHR to exercise (an objective marker of asthma) was no more common among obese children. We also found no significant association between BMI and atopy. These findings confirm those of Schachter $e a^{8}$ in Australian adults although, in a later report, these authors found that high BMI was associated with a higher prevalence of atopy in girls. ${ }^{27}$ In Taiwan, Huang et al ${ }^{14}$ found that BMI was associated with an increased prevalence of BHR and atopy among girls, but for
BHR this was due to a reduced prevalence in the lowest quintile only.

Although many studies have reported sex differences in the effect of obesity on asthma, few studies have reported the significance of the interaction term. ${ }^{13}$ We found no significant interaction with sex for any of the outcomes. However, these tests have low power and, in general, as in other studies, the size of the effect was larger for obese girls than for obese boys. After adjustment for potential confounders, increasing BMI SDS in girls in year 2000 showed significant trends with increases in asthma disease and symptom reporting and asthma medication use. These findings are independent of frequency of hamburger consumption and exercise. We 
Table 4 Adjusted OR (95\% Cl) showing associations for underweight, overweight, and obesity versus normal weight for year 2000 among all children, girls and boys (using the total dataset for 2000)

\begin{tabular}{|c|c|c|c|}
\hline Outcome variables & $\begin{array}{l}\text { Allt } \\
(N=1237)\end{array}$ & $\begin{array}{l}\text { Girls } \\
(N=617)\end{array}$ & $\begin{array}{l}\text { Boys } \neq \\
(N=620)\end{array}$ \\
\hline \multicolumn{4}{|l|}{ Wheeze ever } \\
\hline Underweight & 0.84 (0.41 to 1.72 ) & 0.42 (0.13 to 1.33 ) & $1.58(0.58$ to 4.30$)$ \\
\hline Normal & 1.00 & 1.00 & 1.00 \\
\hline Overweight & $1.02(0.76$ to 1.36$)$ & $1.40(0.92$ to 2.13$)$ & 0.77 (0.50 to 1.18 ) \\
\hline Obese & $1.41(0.90$ to 2.20$)$ & 2.23 (1.18 to 4.22$)$ & $0.88(0.46$ to 1.70$)$ \\
\hline p value & 0.051 & $0.00003^{* \star}$ & \\
\hline \multicolumn{4}{|c|}{ Wheeze in last 12 months } \\
\hline Underweight & 0.49 (0.17 to 1.42$)$ & $0.47(0.10$ to 2.12$)$ & $0.52(0.11$ to 2.35$)$ \\
\hline Normal & 1.00 & $1.00^{\circ}$ & 1.00 \\
\hline Overweight & 1.15 (0.81 to 1.62$)$ & 1.23 (0.74 to 2.03 ) & 1.09 (0.67 to 1.78 ) \\
\hline Obese & $1.95(1.20$ to 3.16$)$ & $1.85(0.92$ to 3.75$)$ & $2.09(1.06$ to 4.15$)$ \\
\hline p value & $0.002^{*}$ & $0.002^{*}$ & 0.17 \\
\hline \multicolumn{4}{|l|}{ Wheeze with exercise } \\
\hline Underweight & 0.35 (0.10 to 1.17 ) & 0.21 (0.03 to 1.59$)$ & 0.48 (0.10 to 2.21$)$ \\
\hline Normal & 1.00 & 1.00 & 1.00 \\
\hline Overweight & 1.15 (0.82 to 1.62$)$ & $1.38(0.85$ to 2.24$)$ & 1.01 (0.61 to 1.65 ) \\
\hline Obese & $1.63(1.01$ to 2.65$)$ & $1.62(0.80$ to 3.27$)$ & $1.82(0.91$ to 3.65$)$ \\
\hline$p$ value & 0.0157 & 0.02 & 0.17 \\
\hline \multicolumn{4}{|l|}{ Asthma ever } \\
\hline Underweight & 1.14 (0.55 to 2.37 ) & $0.93(0.31$ to 2.75$)$ & $1.44(0.51$ to 4.05$)$ \\
\hline Normal & 1.00 & 1.00 & 1.00 \\
\hline Overweight & 1.07 (0.79 to 1.46$)$ & 1.44 (0.93 to 2.24$)$ & 0.86 (0.56 to 1.34$)$ \\
\hline Obese & 1.71 (1.09 to 2.69 ) & 3.10 (1.63 to 5.93 ) & 1.00 (0.52 to 1.93 ) \\
\hline$p$ value & 0.04 & $0.0002^{\star *}$ & 0.48 \\
\hline \multicolumn{4}{|c|}{ Hospital admission ever } \\
\hline Underweight & 2.35 (1.01 to 5.47 ) & $2.23(0.65$ to 7.64$)$ & 2.54 (0.75 to 8.56$)$ \\
\hline Normal & 1.00 & 1.00 & 1.00 \\
\hline Overweight & 1.38 (0.92 to 2.07 ) & $0.92(0.48$ to 1.78$)$ & 1.98 (1.15 to 3.39 ) \\
\hline Obese & $1.63(0.93$ to 2.87$)$ & 2.05 (0.93 to 4.53 ) & $1.03(0.42$ to 2.49$)$ \\
\hline p value & 0.33 & 0.37 & 0.80 \\
\hline \multicolumn{4}{|c|}{ Inhaled steroid or cromoglycates in last 12 months } \\
\hline Underweight & $0.55(0.16$ to 1.84$)$ & $0.36(0.05$ to 2.80$)$ & $0.81(0.18$ to 3.72$)$ \\
\hline Normal & 1.00 & 1.00 & 1.00 \\
\hline Overweight & $1.16(0.78$ to 1.73$)$ & 1.08 (0.60 to 1.94$)$ & 1.30 (0.75 to 2.25$)$ \\
\hline Obese & 2.33 (1.39 to 3.91$)$ & $2.97(1.43$ to 6.18$)$ & $1.98(0.92$ to 4.26$)$ \\
\hline p value & $0.004^{*}$ & $0.003^{*}$ & 0.22 \\
\hline \multicolumn{4}{|c|}{ Medication in last 12 months } \\
\hline Underweight & 0.88 (0.38 to 2.08$)$ & $1.01(0.31$ to 3.24$)$ & $0.78(0.21$ to 2.83$)$ \\
\hline Normal & 1.00 & 1.00 & 1.00 \\
\hline Overweight & $1.22(0.87$ to 1.70$)$ & $1.34(0.83$ to 2.18$)$ & 1.19 (0.74 to 1.91$)$ \\
\hline Obese & 2.07 (1.30 to 3.31$)$ & 2.71 (1.39 to 5.31$)$ & $1.73(0.88$ to 3.42$)$ \\
\hline p value & $0.001^{*}$ & $0.00006^{* *}$ & 0.16 \\
\hline \multicolumn{4}{|l|}{ BHR to exercise } \\
\hline Underweight & $0.36(0.05$ to 2.70$)$ & $0.65(0.08$ to 5.20$)$ & $\S$ \\
\hline Normal & 1.00 & 1.00 & 1.00 \\
\hline Overweight & $0.94(0.56$ to 1.58$)$ & $0.89(0.44$ to 1.81$)$ & $1.04(0.47$ to 2.29$)$ \\
\hline Obese & $0.94(0.44$ to 1.98$)$ & $0.91(0.33$ to 2.47$)$ & $0.96(0.29$ to 3.16$)$ \\
\hline p value & 0.91 & 0.96 & 0.96 \\
\hline \multicolumn{4}{|l|}{ Atopy } \\
\hline Underweight & 0.51 (0.22 to 1.21$)$ & $0.91(0.30$ to 2.71$)$ & 0.25 (0.06 to 1.13 ) \\
\hline Normal & 1.00 & 1.00 & 1.00 \\
\hline Overweight & 1.05 (0.78 to 1.43 ) & $0.83(0.53$ to 1.30$)$ & $1.31(0.86$ to 2.01$)$ \\
\hline Obese & $1.44(0.91$ to 2.28$)$ & $1.47(0.76$ to 2.84$)$ & $1.45(0.76$ to 2.78$)$ \\
\hline p value & 0.016 & 0.32 & 0.012 \\
\hline \multicolumn{4}{|c|}{ 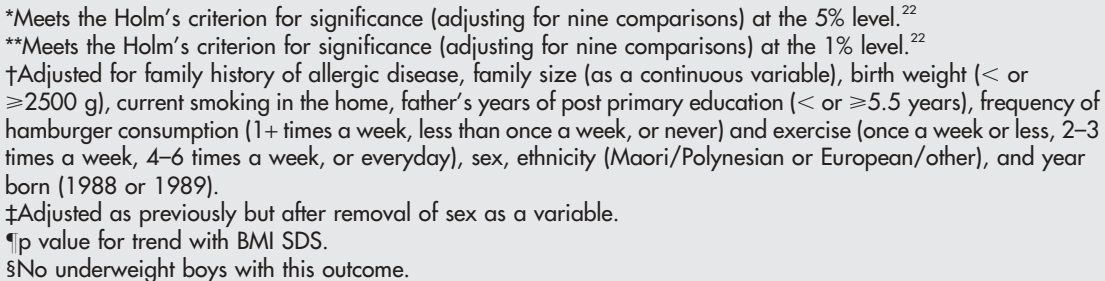 } \\
\hline
\end{tabular}

acknowledge the limitations in defining food consumption and exercise frequency according to questionnaire based reports. However, few other studies ${ }^{6}$ have been able to adjust for these potential confounders, both of which have previously shown associations with asthma. ${ }^{28-31}$

As an explanation for the predominance of asthma in obese women and girls, ${ }^{711215}$ in a recent review Tantisira et $a l^{32}$ discuss the possibility that obesity amplifies the proinflammatory effects of leptin and oestrogens in women.
Furthermore, obese girls reach puberty earlier than nonobese girls. ${ }^{33}$ Although some girls in the current study would have reached puberty, we did not collect this information. However, studies of prepubescent children ${ }^{11} 13$ showing a greater risk of asthma among obese girls would tend to refute this hypothesis, unless prepubescent children are exposed to sources of environmental oestrogens, such as in food, which become concentrated in adipose tissue. 
Obesity may also develop as a consequence of asthma if the disease leads to a sedentary lifestyle. However, reverse causation is an unlikely explanation for the association since prospective studies have shown that obesity precedes the onset of asthma ${ }^{12}{ }^{15}$ and interventions that reduce obesity in asthmatics are followed by improvements in airways obstruction, peak flow variability, and symptoms. ${ }^{16}{ }^{17}$

There is some evidence for an association of BMI with asthma but this does not explain the increasing prevalence of asthma. Despite indications in our data and others ${ }^{11}{ }^{13}{ }^{14}$ that this association is stronger in girls, we failed to show significant interactions with sex. The exact nature of the effect of obesity on asthma needs to be further explored prospectively in large cohort studies.

\section{ACKNOWLEDGEMENTS}

The authors thank Donna Moana, Karen Wright, Bobby Munro, Julie Benton, Dr Wendy Gush, Dr Diane Wilson and Dr Nicola Butler for assistance during the field work in schools, Juliette Lane for clerical assistance, and the schools and their pupils and families that participated in the study.

\section{Authors' affiliations}

K Wickens, J Crane, Wellington Asthma Research Group, Wellington School of Medicine and Health Sciences, New Zealand

D Barry, N Bone, Healthcare Hawkes Bay, Hastings, New Zealand

A Friezema, R Rhodius, Faculty of Medicine, University of Groningen, The Netherlands

G Purdie, Department of Public Health, Wellington School of Medicine and Health Sciences, New Zealand

This research was assisted by grants from the Hawkes Bay Medical Research Foundation, the Health Research Council of New Zealand, and the Asthma and Respiratory Foundation of New Zealand.

\section{REFERENCES}

1 Bundred P, Kitchiner D, Buchan I. Prevalence of overweight and obese children between 1989 and 1998: population based series of cross sectional studies. BMJ 2001;322:326-8.

2 Simmons G, Jackson R, Swinburn B, et al. The increasing prevalence of obesity in New Zealand: is it related to recent trends in smoking and physical activity. NZ Med J 1996;109:90-2.

3 Turnbull A, Barry D, Wickens K, et al. Changes in body mass index in 11-12year-old children in Hawkes Bay, New Zealand (1989-2000). J Paediatr Child Health 2004;40:33-7.

4 Burr ML, Butland BK, King S, et al. Changes in asthma prevalence: two surveys 15 years apart. Arch Dis Child 1989;64:1452-6.

5 Mitchell EA, Asher MI. Prevalence, severity and medical management of asthma in European school children in 1985 and 1991. J Paediatr Child Health 1994;30:398-402.

6 Carmargo CA, Weiss ST, Zhang S, et al. Prospective study of body mass index, weight change, and risk of adult-onset asthma in women. Arch Intern Med 1999;159:2582-8.

7 Shaheen SO, Sterne JAC, Montgomery SM, et al. Birth weight, body mass index and asthma in young adults. Thorax 1999;54:396-402.
8 Schachter LM, Salome CM, Peat JK, et al. Obesity is a risk for asthma and wheeze but not airway hyperresponsiveness. Thorax 2001;56:4-8.

9 Jarvis D, Chinn S, Potts J, et al. Association of body mass index with respiratory symptoms and atopy: results from the European Community Respiratory Health Survey. Clin Exp Allergy 2002;32:831-7.

10 von Mutius E, Schwartz J, Neas LM, et al. Relation of body mass index to asthma and atopy in children: the National Health and Nutrition Examination Study III. Thorax 2001;56:835-8.

11 von Kries R, Hermann M, Grunert VP, et al. Is obesity a risk factor for childhood asthma? Allergy 2001;56:318-22.

12 Castro-Rodriguez JA, Holberg CJ, Morgan WJ, et al. Increase in incidence of asthmalike symptoms in girls who become overweight or obese during the school years. Am J Respir Crit Care Med 2001;163:1344-9.

13 Figueroa-Munoz JJ, Chinn S, Rona RJ. Association between obesity and asthma in 4-11 year old children in the UK. Thorax 2001;56:133-7.

14 Huang L, Shiao GM, Chou P. Association between body mass index and allergy in teenage girls in Taiwan. Clin Exp Allergy 1999;29:322-9.

15 Chen $Y$, Dales $R$, Tang $M$, et al. Obesity may increase the incidence of asthma in women but not in men: longitudinal observations from the Canadian National Population Health Surveys. Am J Epidemiol 2002;155:191-7.

16 Hakala K, Stenius-Aarniala B, Sovijarvi A. Effects of weight loss on peak flow variability, airways obstruction, and lung volumes in obese patients with asthma. Chest 2000;118:1315-21.

17 Stenius-Aarniala B, Poussa T, Kvarnstrom J, et al. Immediate and long term effects of weight reduction in obese people with asthma: randomised controlled study. BMJ 2000;320:827-32.

18 Chinn S, Rona RJ. Can the increase in body mass index explain the rising trend in asthma in children? Thorax 2001:56:845-50.

19 Asher MI, Keil U, Andersen HR, et al. International study of asthma and allergies in childhood (ISAAC): rationale and methods. Eur Respir J 1995;8:483-91.

20 Cole TJ, Bellizzi MC, Flegal KM, et al. Establishing a standard definition for child overweight and obesity world wide: international survey. BMJ 2000;320:1240-3.

21 Williams S. Body mass index reference curves derived from a New Zealand birth cohort. NZ Med J 2000;1 13:308-11.

22 Aicken M, Gensler H. Adjusting for multiple testing when reporting research results: the Bonferroni vs Holm methods. Am J Public Health 1996:86:726-8.

23 Chinn S. Obesity and asthma: evidence for and against a causal relation. $J$ Asthma 2003;40:1-16

24 Peckham C, Butler N. A national study of asthma in childhood. J Epidemiol Community Health 1978:32:79-85.

25 Kaplan BA, Brush G, Mascie-Taylor CGN. The relationship of childhood asthma and wheezy bronchitis with height, weight and body mass index. Human Biology 1987;59:921-31.

26 Somerville S, Rona R, Chinn S. Obesity and respiratory symptoms in primary school children. Arch Dis Child 1984;59:940-4.

27 Schachter L, Peat J, Salome C. Asthma and atopy in overweight children. Thorax 2003;58:1008-10.

28 Rasmussen F, Lambrechtsen J, Siersted HC, et al. Low physical fitness in childhood is associated with the development of asthma in young adulthood: the Odense schoolchild study. Eur Respir J 2000;16:866-70.

29 Barr RG, Cooper DM, Speizer FE, et al. Beta(2)-adrenoceptor polymorphism and body mass index are associated with adult-onset asthma in sedentary but not active women. Chest 2001;120:1474-9.

30 Robertson $\mathrm{C}$. The association between fast food outlets and the prevalence of symptoms of asthma from the International Study of Asthma and Allergies in Childhood (ISAAC). Eur Respir J 1998;12(Suppl 28):244s.

31 Hijazi N, Abalkhail B, Seaton A. Diet and childhood asthma in a society in transition: a study in urban and rural Saudi Arabia. Thorax 2000;55:775-9.

32 Tantisira KG, Weiss ST. Complex interactions in complex traits: obesity and asthma. Thorax 2001;56(Suppl II):ii64-73.

33 Anderson S, Dallal G, Must A. Relative weight and race influences average age at menarche: results from two nationally representative surveys of US girls studied 25 years apart. Pediatrics 2003;111:844-50. 